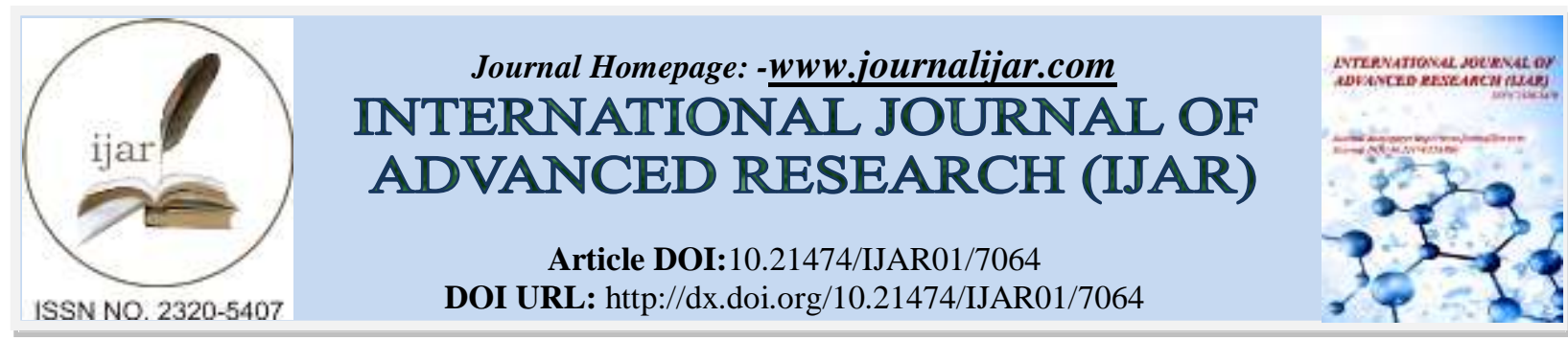

RESEARCH ARTICLE

\title{
FACTORS RESPONSIBLE FOR STUDENTS' DROPOUT AT SECONDARY EDUCATION AMONG SLUM CHILDREN: A STUDY ON KHULNA CITY OF BANGLADESH
}

\author{
Sk. Sharafat Hossen ${ }^{1}$, Afsana Akter Hira ${ }^{2}$ and Kaniz Fatima Mohsin ${ }^{3}$ \\ 1. Associate Professor Economics Discipline Khulna University Khulna-9208, Bangladesh. \\ 2. MSS Student Economics Discipline Khulna University Khulna-9208, Bangladesh. \\ 3. Associate Professor Economics Discipline Khulna University Khulna-9208, Bangladesh.
}

\section{Manuscript Info \\ Manuscript History \\ Received: 08 March 2018 \\ Final Accepted: 10 April 2018 \\ Published: May 2018}

Keywords:-

Dropout, Financial Constraint, Illiteracy,

Early Marriage

\begin{abstract}
In Bangladesh, the significant proportion of slum children who are enrolled in class six (beginning of secondary education) cannot complete their secondary education. Dropout of slum children from their secondary education is not a new challenging issue in Bangladesh and it is interrelated to multiple factors. The objective of this paper is to investigate the factors responsible for students' dropout at secondary level among slum children in Khulna city of Bangladesh. A total of 150 slum children of Khulna city participated in the study where 75 were drop out and rest 75 were non-dropout students from secondary level of education. They were randomly selected from three slum areas of Khulna city. Data were collected through interview method with wellstructured interview schedule. The research is quantitative in nature and obtained data were analyzed by using both descriptive and inferential statistics. A logistic regression model was run to find out the likelihood of being dropout and it shows that parents' illiteracy, greater dependency ratio, financial constraints, involvement in income generation activities and early marriage are increasing the probability of dropout and also worsening the dropout scenario. Among the dropout students, maximum girls got married and majority of the boys engaged in different income generating activities as per the requirement of their family. The study recommends that tuition fee of schools can be reduced to decrease their dropout decision from secondary education. The study also recommends that government should run stipend program for slum children to save them from dropping out from secondary education.
\end{abstract}

Copy Right, IJAR, 2018,. All rights reserved.

\section{Introduction:-}

Dropout is a pervasive problem in the education system of Bangladesh. It is a great challenge to increase educational attainment because about 50.00 percent of the students admitted to class one across the country drop out before completing class five and 80.00 percent from secondary level (CAMPE, 2007). Bangladesh has achieved significant improvement in enrolment in primary and secondary education but in case of reducing dropout, the situation is not that much satisfactory. According to DPE (2014), at national level, the gross enrolment was 108.00 percent and 69.00 percent respectively; net enrolment was 98.00 percent and 64.00 percent in primary and secondary education 
respectively. The cohort dropout was 20.00 percent in primary and 42.00 percent in secondary level. Areas with lower literacy, the rates of dropout are huge (Chugh, 2011) and girls tend to have larger dropout rates than boys (Shahidul and Karim, 2015; Chugh, 2011).

The children living in remote areas/urban slums are more likely to be dropped out from school. Many children are unable to complete secondary education and multiple factors are responsible for dropping out of school. Financial constraints, low level of literacy among parents, weaker family structure or family bondage and lack of pre-school experiences are the main factors of dropping out of students (Chugh, 2011). Besides poverty and financial constraints, distance of school, inadequate teacher-student relationship, inadequate resource and facilities as well as irrelevant curriculum are responsible for student dropout (Shadreck, 2013). Though the education stipend program of Bangladesh has great achievement in terms of educational outcome but this program are confined to rural areas. The urban slum children are deprived of such incentives (FREPD, 2015).

According to Shadreck (2013) the major concern today is to reduce the dropout rate so the students could complete their education. Because dropout from education is not an individual problem rather it is a social problem and it has a huge cost for the economy in the long run.

In Bangladesh, about 40 million people live in urban areas out of which 21 percent live below poverty line. This poor people live in slum areas and have limited access to education (FREPD,2015). There are a number of slum children who drop out before completing their secondary education. The dropout children are, in most cases, deprived of basic needs and the formation of human capital is obstructed. The study focused on the potential issues that might have influence on children dropout. The authors try to give some new insights which are not available in literature. A few works have been done on the topic but neither of them concentrated on the area that the study covers. The geographical position of the region itself depicts some different characteristic features like excessive natural hazard induced rural-urban migration which is increasing the growth of urban slum and the city area is struggling to meet up the basic needs of the city dwellers including slums. The study can be useful to the policy makers to control the dropout of slum children at secondary level.

The objective of the study is to identify the factors of students' dropout at secondary level education among slum children in Khulna city.

\section{Literature Review:-}

The developing countries have large number of vulnerable children groups such as rural and urban poor children, girls of rural and urban poor, children of religious and ethnic minority groups and disable children (Latif, 2005). The most vulnerable groups in Bangladesh are those who are poor and female, poor and indigenous and poor with special needs. They face a 'double disadvantage' of being poor as well as being marginalized. These three groups face severe disadvantages in education because their needs are often neglected and often curriculum, school infrastructure, learning materials and teachers exclude them from the educational process (Ahmed et al., 2009). Access to education is a basic human rights which has been recognized as universal (Ahmad, 2014). Mujeri (2010) states in his paper that state must take adequate measures to eliminate obstacles of increasing the access to education of those vulnerable groups of children.

Hussain et.al (2011) examines that the causes of high dropout rate at primary level in Pakistan are higher tuition fee, larger distance from home to schools, attitude of teachers, reluctance of parents, and inconvenient curriculum of schools. According to a study on the marginalized slum children in Delhi, Chugh (2011) concludes that both family and school related factors are responsible for student' dropout.

Dey (2016) points out that majority of the drop out children have illiterate parents. This finding is consistent with the study findings of Ersado (2005) which confirms that education level of household members is influential particularly on children and it determines their access to education. Many scholars argued that the education of parents is linked to children's retention of school. It is not possible for non-educated parents to provide or appreciate the advantage of being educated (Juneja, 2001). Educated parents assist their children in preparing their assignment but the illiterate parents of poor families can not do it and so students get dropped out finding no interest in the class activities (Zaman, 2014). Lower educational status of parents is one of the contributing factors of the low rate of completion of education of the children (Chugh, 2011). 
Chugh (2011) states that family size influences the children drop out. Children with more siblings tend to enroll later as well as drop out earlier. He also finds that during any financial crisis, schooling of the children becomes the first matter thought to skip to face the shock in poor households. Besides, children engage in income generating activities result high rate of school dropout.

It is tough to draw direct relationship between child labor and education because of the interplay and interdependency of multiple factors. However, evidence suggests a strong relationship between the prevalence of child labour and education. For example, nearly 50.00 percent of children dropout at primary level education caused due to their candidature in the labour market (ILO, 2004). This child labor prevails because most employers are willing to exploit children and they are cheap, docile, unskilled labor. By employing children on very low wages, employers are able to maximize their profits (Majumdar, 2001).

It is logical to assume that child labors do not think that school is the medium to attain higher income or for developing expertise and competencies. Children who are engaged in worst forms of child labor (WFCL), 41.30 percent did not have any general or pre-vocational training before entering child labor. Hence, it is possible that households send their children to work because they believe that the child is more likely to learn the skills they need on the job rather than in school (Ahmed et al., 2009). Fares and Raju (2007) in their study show empirical evidence that countries with higher rates of working children also have higher rates of children not attending school.

When gender issue is considered with overall, a bit different picture is seen in our society. Although the class attendance of girls is high, their possibility to be enrolled in the next class is lower. Girls' dropout rate is higher than that of boys at secondary schools and their achievement scores tend to be significantly lower especially in rural areas and among the urban poor in least developed countries (UNICEF, 2008). Many families still keep their girls out from school simply because they do not believe a girl needs or should be educated. Many girls are married at very young ages. Islam and Pavel (2011) state in their paper that women are always deprived of their education due to early marriage and married girls have to leave their educational institution because their husband and in-laws prohibit continuing education. In the rural areas, girls are frequently kept confined at home to perform the household chores. Thus, gender parity has not been achieved fully in the primary school enrollment. In many cases girls have higher enrollment rate than boys. But the problem arises in regular attendance in class which is worst for the girls from poor families (Hekela, 2014).

From the literature we can see that lots of works have been done on students' dropout. Some authors work on dropout at primary level, some at secondary level and some works on both primary and secondary level. These works have been done on different countries such as Bangladesh, India, Pakistan, Zimbabwe, Tanzania etc. But no study compares between dropout and non-dropout students to find out the factors of dropout. Again the researchers use logit model to get an estimated result of these factors behind the dropout which is absent in most of the literature. Avoiding country level aspects, this study is confined in a limited city area with an intension to make an intensive study focusing the topic and this is strongly believed that this effort will contribute to the existing body of knowledge.

\section{Data and Methods:-}

The researchers collected data from three slum areas of ward no. 19, 20 and 21 in Khulna City on the basis of random sampling technique. All high school going and dropout students at secondary level in slum areas of theses wards were the population of the study. The total sample size was restricted to 150 slum children aged between 11 16 years which is the high school age of children. The sample was divided into 75 school going and 75 dropout children at secondary level to find out the factors of students' dropout. Data had been collected through interview method with structured questionnaire with the interviewee.

The research is quantitative in nature because both descriptive and inferential statistical tools had been used for data analysis. In addition, a logistic regression model had been run to find out the factors which can be responsible behind the dropout of students in Khulna city as the dependent variable is a binary one. 


\section{Result and Discussion:-}

Age of the Respondents:-

As the study is on the secondary school dropout issue and there are two group, dropout and non-dropout students, so the age is between 11 to 16 years which is the high school age of respondents.

Table 01:-Age of the Respondents

\begin{tabular}{|c|c|c|c|}
\hline Age limit & & Frequency & Percent \\
\hline $11-12$ & & 28 & 18.67 \\
\hline $13-14$ & & 63 & 42.00 \\
\hline $15-16$ & & 59 & 39.33 \\
\hline Total & & 150 & 100.00 \\
\hline Minimum: 11 & Maximum: 16 & Mean: 13.91 & \\
\hline
\end{tabular}

Source: Authors Compilation Based on Field Survey, September-October, 2017

Table 01 shows that the age group 13 to 14 years has the highest frequency (63) in sample. Again the mean of the age distribution is 13.91 which also remains between 13 to 14 years. Dey (2016) has the highest respondents of 16 to 18 years and Chugh (2011) has the highest respondent of 15 to 16 years. In our study the highest age group 15 to 16 years has the frequency 59 which represents 39.33 percent of total respondents. It indicates that this study is comparable to Dey (2016) and Chugh (2011).

\section{Sex Ratio of the Respondents:-}

In case of children drop out in schools, drop out is gender irrespective; dropout is quite prevalent in both the sex. To compare the issue of dropout the researcher takes dropout and non-dropout students and both the groups includes boys and girls.

Figure 01:-Sex Ratio of Dropout and Non-dropout Students

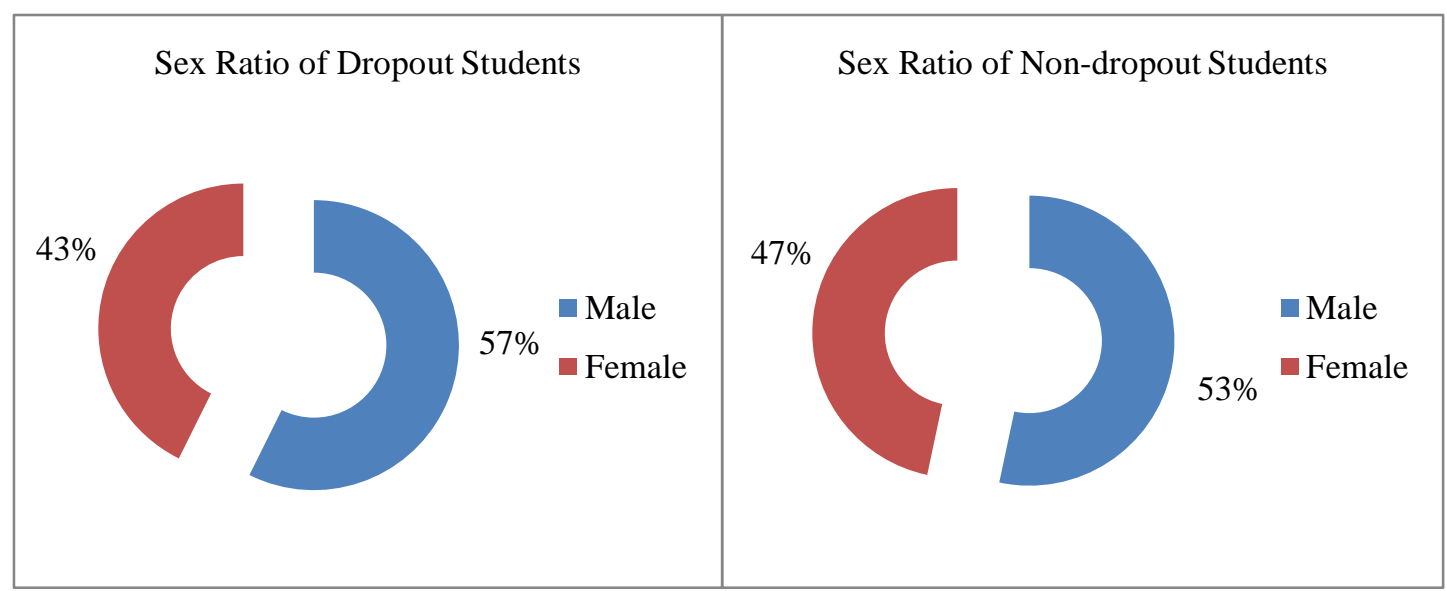

Source: Authors Compilation Based on Field Survey, September-October, 2017

If we look at figure 01 we can see that in total selected sample, the frequency of boys is higher than girls and again if we compare between the two groups, the percentage of boys is higher in both the groups. In dropout group, the percentage of boys and girls are 57.00 percent and 43.00 percent respectively while in non-dropout group, the distribution is 53.00 percent and 47.00 percent respectively.

The concentration of dropping out is higher among the boys. Lower family income is the main background cause of boy's dropout as in many cases; the boys left school and join the labor force which increases the prevalence of child labor as their age ranges between 11-16 years.

\section{Family Size of the Respondents:-}

Chugh (2011) reveals in his paper that family size is an important factor for dropping out of students. Households with larger family size enroll their children later and also these children drop out earlier. Families with larger family 
size tend to face higher mismatch in earning and expenditure and as such, face higher difficulty to pay for education of children (Shadreck, 2013; Hussain et al., 2011).

Figure 02 shows that the family size of dropout students is larger than that of non-dropout students. In case of dropout students, the family size with seven members has the highest frequency while in case of non-dropout student, family size with five members has the highest frequency.

Figure 2:-Family Size of Dropout and Non-dropout Students



Source: Authors Compilation Based on Field Survey, September-October, 2017

Again we also notice that there are families with eight and nine members in the dropout group but in the case of non-dropout group, there is no family with such large family size.

Family size has direct relation with family expenditure. As family size increases, expenses on direct consumption increases, it is really hard for the poor families to recognize the need for education as a result of which the families simply regret to bear the educational expenses and that is why among the larger families, dropout rate is higher than the smaller families.

\section{Family Type of the Respondent:-}

The pie charts in figure 03 present family type of dropout and non-dropout students. There are two categories -joint and nuclear. If we look at the pie charts we can see that in both types of students, the frequency of nuclear family is larger than joint family which is a common feature of urban family structure. In dropout students, nuclear family is 63.00 percent while for non-dropout students, it is 85.00 percent. But if we compare the prevalence of joint family, then we find that the presence of joint family is higher in drop group than non-dropout group. We can see that it is 37.00 percent for dropout students but it is only 15.00 percent for non-dropout students. 
Figure 03:-Family Type of Dropout and Non-dropout Students



Source: Authors Compilation Based on Field Survey, September-October, 2017

\section{Socio-Demographic Profile of Respondents:-}

From the socio-demographic profile of dropout and non-dropout students we can see that the mean age of household heads of dropout students is greater than the mean age of household heads of non-dropout students (table 02).

Table 02:-Socio-demographic Profile of the Respondents

\begin{tabular}{|l|r|r|r|r|}
\hline \multirow{2}{*}{ Socio-demographic Profile } & \multicolumn{2}{|c|}{ Dropout Students } & \multicolumn{2}{c|}{ Non-dropout Students } \\
\cline { 2 - 5 } & \multicolumn{1}{|c|}{ Mean } & \multicolumn{1}{c|}{ Std. Dev. } & \multicolumn{1}{c|}{ Mean } & \multicolumn{1}{c|}{ Std. Dev. } \\
\hline Age of Household Head & 48.97 & 7.25 & 37.31 & 5.25 \\
\hline Earning Member & 1.43 & 0.49 & 1.49 & 0.50 \\
\hline Dependent Member & 4.92 & 0.98 & 3.47 & 0.95 \\
\hline Monthly Income of Households & 4825.33 & 904.51 & 5646.67 & 1114.32 \\
\hline Years of Schooling of Respondents & 8.44 & 1.02 & 6.77 & 0.88 \\
\hline Years of Schooling of Parents & 2.57 & 3.23 & 3.84 & 3.46 \\
\hline
\end{tabular}

Source: Authors Compilation Based on Field Survey, September-October, 2017

But the average earning member, average monthly income of households and years of schooling of parents of dropout students are less than that of non-dropout students. On the other hand, average dependent member, average years of schooling of dropout respondents are larger than that of non-dropout students.

\section{Sex Ratio of Household Head:-}

Household head is an important factor for dropping out of students. The following pie charts show us the malefemale ratio of household head of dropout and non-dropout students. If we look at the pie charts in figure 04, they indicate that the prevalence of female headed households is larger in dropout group than that of non-dropout group. But in both the pie charts, the maximum families' household heads are male and it is 63.00 percent in case of dropout students and 88.00 percent for non-dropout students. 
Figure 4:-Gender Ratio of Household Head

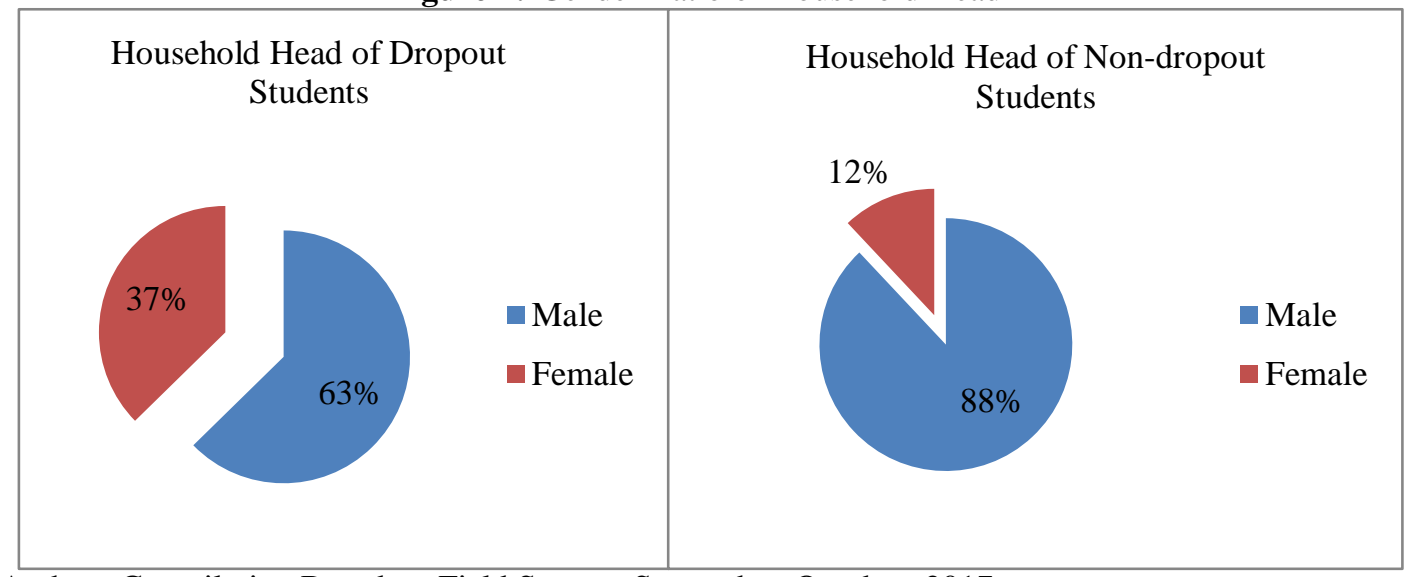

Source: Authors Compilation Based on Field Survey, September-October, 2017

Here, the dropout rate is higher among the female headed households. Normally, the safety nets is so poor in developing nations that is why, when the male members are absent, it is really hard for the females to bear family expenses due to the lower employment opportunity and acute discriminated wage between male and female. That is why boys or girls, skip schooling to earn income and specifically the girl, the reason might be to earn income or to take care the siblings on behalf of her working mother.

\section{Last Academic Performance of Dropout Student:-}

In the opinion of many scholars is that children living in the slum areas have very poor academic performance because they have no favorable academic environment. Figure 05 shows last academic performance of dropout students.

Figure 5:-Last Academic Performance of Dropout Students

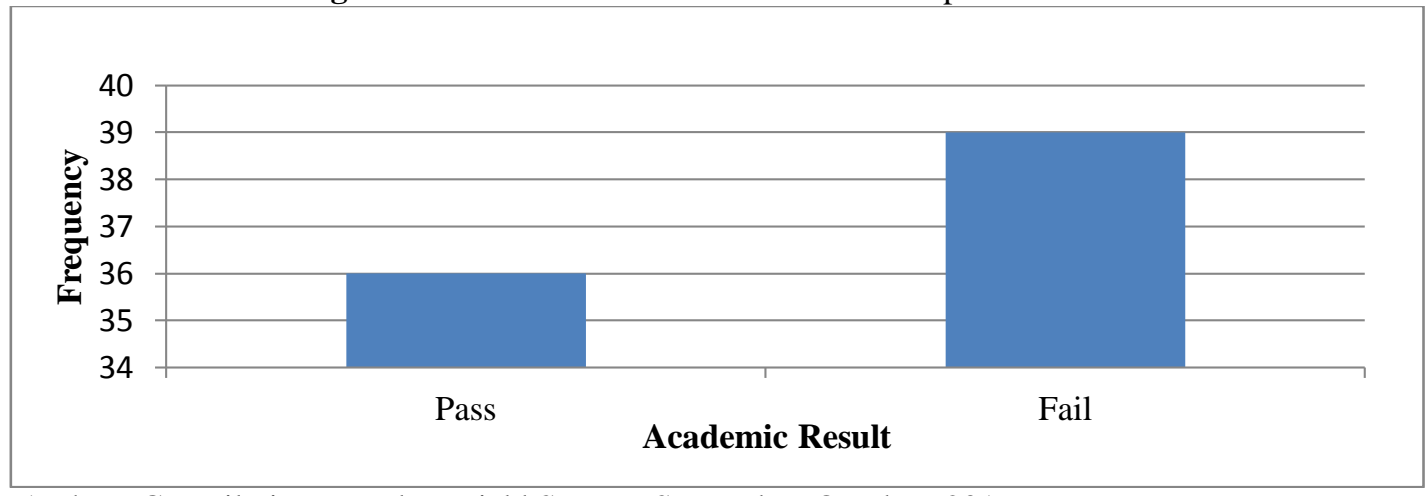

Source: Authors Compilation Based on Field Survey, September-October, 2017

From the study, it is found that out of 75 dropout students, 39 students fail in their last academic examination. That is the majority of dropout students cannot pass their last examination. Only 36 dropout students out of 75 pass in their exam. In this case when poor parents realize that their children could not have success in their study, they prefer dropout. So we can say that examination result is an important factor behind the dropout of students.

Academic achievement works as an inspiration of further study but when that performance is poor, then the students themselves as well as their parents become reluctant to continue study.

\section{Tuition Fee:-}

Cost of schooling is one of the most significant factors of dropping out of students (Chugh, 2011). A total of 50 respondents out of 150 have tuition fee 60-100 in BDT per month. The frequencies of tuition fee ranging BDT 210250 and BDT 260-300 were 9 and 4 respectively. Majority of respondents has tuition fee ranging between 110-150 in BDT per month and it incorporates 66 respondents out of 150 . 
Though the tuition fee might seems not so high if we compare to total household expenditure, for low income parents it is much burdensome to pay the tuition fee per month regularly because they need to bear other related cost of education (cost of supplementary books, study materials and equipments) for their children. In many cases, seasonality of parents' occupation, seasonality of production and other economic shocks create uncertainty to continue children's education and promotes dropout.

\section{Involvement in Income Generating Activities of Dropout Students:-}

Children's engagement in income generation may also responsible for their school dropout. When children are dropped out from their secondary education, they could easily involve in earning activities (Chugh, 2011). It is found from the data analysis that after the dropping out, 55 percent children have involved in earning activities (see figure 06).

Figure 06:-Involvement in Earning Activities of Dropout Students

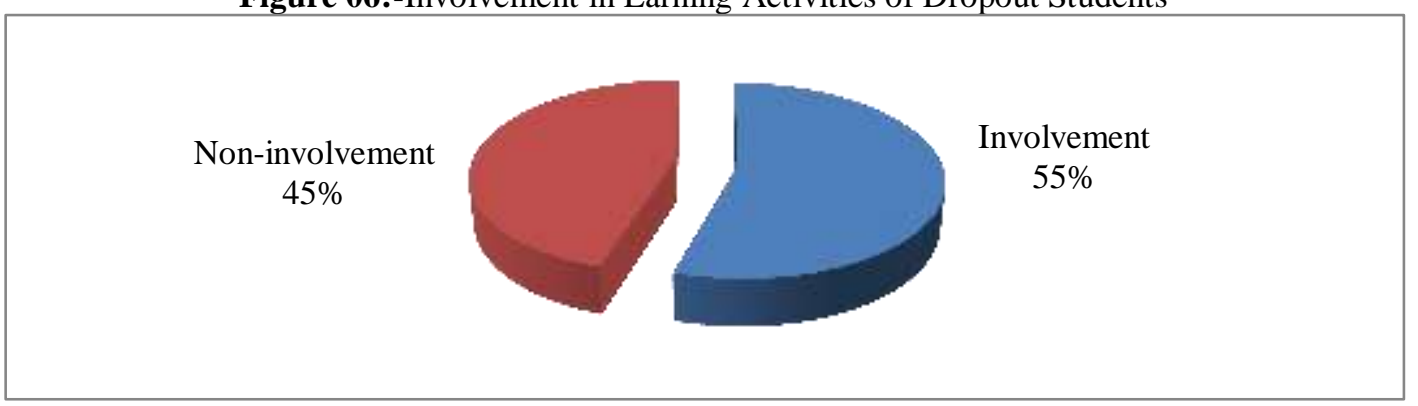

Source: Authors Compilation Based on Field Survey, September-October, 2017

Figure 06 shows that majority of dropout students involve in earning activities. Male dropout students involve either in garage, factory or any small shop. The female dropout students involve as house maid or factory worker. As we have mentioned it earlier, income earning is a strong background of school dropout and as the frequency of boys is higher, the majority of dropped out children are engaged in income earning.

\section{Marital Status of Dropout Girls:-}

Early marriage is one of the important factors for dropping out of girls. After marriage, these girls do not go to school and thus they are dropped out (Chugh, 2011). It is found from the analysis that out of 32 dropout girls, 24 got married and dropped out. These dropped out girls have no option to return in schools.

Association between Students' Dropout and Potential Influential Factors:-

The association between students' dropout at secondary level and its related factors are shown in table 03 and we can see that the values of Chi-square between students' dropout and all the related factors are statistically significant at $1 \%$ level of significance; thus it confirms that there are significant associations between students' dropout and selected potential factors.

Table 03:-Association between Students' Dropout and its Factors

\begin{tabular}{|c|c|c|c|}
\hline \multicolumn{2}{|c|}{ Association Between } & Value of Chi-Square & P Value \\
\hline \multirow{9}{*}{ 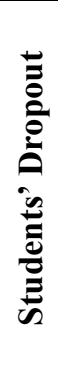 } & Factors & - & - \\
\hline & Age of the Respondent & 31.19 & 0.00 \\
\hline & Age of Household Head & 16.95 & 0.00 \\
\hline & Gender of Household Head & 14.62 & 0.00 \\
\hline & Monthly Income of Household & 22.78 & 0.00 \\
\hline & Family Type of Household & 8.73 & 0.00 \\
\hline & Tuition Fee & 29.71 & 0.00 \\
\hline & Involvement in Income Generation Activity & 37.96 & 0.00 \\
\hline & Marital Status & 25.39 & 0.00 \\
\hline
\end{tabular}

Source: Authors Calculation Based on Field Survey, September-October, 2017 


\section{Analysis of Model:-}

A logistic regression has been run to analyze the influence of factors behind dropping out of students at secondary level among slum children. The result of this model is shown in table 04.Two types estimation - basic coefficient and marginal effect have been used to predict the result. The estimation results are shown by two columns respectively.

Table 04:-Estimated Result for Logistic Regression Model

\begin{tabular}{|l|r|r|}
\hline Dependent Variable: Students' Dropout (Yes = 1, No $=\mathbf{0})$ \\
\hline Explanatory Variables & Basic Coefficient & Marginal Effect \\
\hline Age of the Respondent & $0.729^{* * *}(0.267)$ & $0.168^{* * *}(0.064)$ \\
\hline Sex of the Respondent & $1.747^{*}(0.974)$ & $0.392^{*}(0.198)$ \\
\hline Family Type & $1.181(1.351)$ & $0.282(0.315)$ \\
\hline Dependency Ratio & $0.072(0.271)$ & $0.312(0.064)$ \\
\hline Gender of Household Head & $-2.569^{*}(1.346)$ & $-.438^{*}(0.140)$ \\
\hline Age of Household Head & $0.250^{* * *}(0.0932)$ & $0.058^{* * *}(0.021)$ \\
\hline Income in Thousands of BDT & $-0.562(0.377)$ & $-0.129(0.087)$ \\
\hline Parent Education & $-0.367 * *(0.147)$ & $-0.085^{* *}(0.035)$ \\
\hline Tuition Fee & $0.0332^{* * *}(0.0114)$ & $0.008^{* * *}(0.003)$ \\
\hline Involvement in Income Generation Activity & $4.143^{* * *}(1.018)$ & $0.643^{* * *}(0.095)$ \\
\hline Marital Status & $5.611^{* * *}(1.933)$ & $0.587^{* * *}(0.104)$ \\
\hline Constant & $-22.97 * * *(6.466)$ & $-22.97 * * *(6.466)$ \\
\hline Observations & $\mathbf{1 5 0}$ & \\
\hline \multicolumn{2}{|c|}{ Dependent Variable: Dropout at Secondary Level } \\
\hline
\end{tabular}

Standard errors in parentheses; $* * * \mathrm{p}<0.01, * * \mathrm{p}<0.05, * \mathrm{p}<0.1$

Source: Authors Estimation based on Field Survey, September-October, 2017

The result shows that all the selected variables were significantly influencing children drop out except family type, dependency ratio and income. Age of the respondent is significant at 1 percent level, sex of the respondent and gender of household head is significant at 10 percent level. Age of the household head is significant at 1 percent level and parent education is significant at 5 percent level. Tuition fee, involvement in income generating activity and marital status are also significant at 1 percent level.

From the third column in table 04 we can see the marginal effect which can predict the probability of change in dependent variable due to change in independent variable. If the age of respondent increases by one year the probability of becoming dropped out increases by 16.00 percent. The positive marginal effect of gender of respondent means that boys have greater probability to drop out from the secondary level than girls and this result supports the findings of Dey (2016).

If family type of respondent is joint rather than nuclear then the probability of dropping out of respondent increases by 28.00 percent. If dependency ratio increases by 1.00 unit, then the likelihood of becoming dropped out of respondent increases by 31.00 percent. This findings is consistent with Chugh (2011). But there is less likelihood of being dropped out of respondent if the head of household is male instead of female. The result also shows that if the age of household head increase by one year then the probability of becoming dropped out of respondent increases by 5.80 percent.

There is negative relationship between income and children dropout. If the income increases by BDT one thousand the probability of being dropout of respondents decreases by 13.00 percent. This result supports the findings of Dey (2016) and Chugh (2011). If the tuition fee of respondent increases by BDT 100, then the possibility of being dropout increases by 0.80 percent. If the respondent involves in any earning activities, the probability of being dropout can be increased by 64.00 percent. Here marital status has also positive marginal effect that means that if the respondent is married then the probability of being dropout increases by 59.00 percent. 


\section{Conclusion:-}

In Bangladesh, each year, many students in slum areas dropped out before completing their secondary education. This dropout issue is a complex phenomenon and it is related with many factors. The study has tried to identify those factors and it confirms some factors like greater dependency ratio, age and gender of household head, low earning in the family, poor parental education, poor academic performance of students, early marriage and involvement in income generating activities of students. Each of the identified determinants have multidimensional impact on the society. Larger dependency ratio needs demographic interventions like induce families to restrict family size but religious beliefs and cultural barriers like son biasness or lack of safety nets nullifies all fertility reduction interventions. Unavailability of social safety nets make the aged household headed families more vulnerable about their future uncertainty and promotes dropout. Again in case of poor academic performance of slum children, there is more to do with the income earning capacity for the families rather than the quality of education as being scared about the daily necessities like food or shelter, it is really tough to concentrate on education both for children and parents. Early marriage is another important barrier towards girl's education which further resulted in immature birth, higher infant and maternal mortality and higher fertility. Lack of access to employment, patriarchal society all are deteriorating girl's position in the family. So, if we want to address dropout of children, we have to consider all those barriers and work simultaneously in all the sectors that are affecting those determinants. In addition, illiterate parents with the low earning capacity cannot realize the value of education and they want their children to get involved in earning to augment their family income and hence increase the probability for their children to be dropped out from school. Besides after dropout, these children who got involved in earning do not get proper value of their labor and they are exploited by employers. Well established theory suggests that, child labor prevalence can be reduced considerably if income of the adults could be improved. Imposition of minimum wage, introducing evening school for working children and programs like school feeding might be some interventions that may reduce school dropout at high school level. As it is identified that high tuition fee is one of the factors of students' dropout, the study recommends that tuition fee of schools can be reduced to decrease the students' dropout decision from secondary education. The study also recommends that government should run stipend program for slum children to save them from dropping out from secondary education.

\section{References:-}

1. Ahmed, M. Uddin, L. and Hossain, A. (2009): Child Labor and Education in Bangladesh, Bangladesh Education Journal.

2. CAMPE (2007): Campaign for Population Education (CAMPE), Dhaka, Bangladesh.

3. Chugh, S. (2011): Dropout in Secondary Education, Occasional Paper, No. 37, National University of Educational Planning and Administration, India.

4. Dey, D.K. (2016): Process on how decisions are made and why around drops out-A case study of School Dropouts in Mahbubnagar district of Telangana State, India, World Journal of Educational Research, 3(3).

5. DPE (2014): Bangladesh Primary Education Annual Sector Performance Report -2014, Department of Primary Education, Bangladesh (DPE), Ministry of Primary and Mass Education Government of the People's republic of Bangladesh.

6. Ersado, L. (2005): Child Labor and Schooling Decisions in Urban and Rural Areas: Comparative Evidence from Nepal, Peru, and Zimbabwe, 33(3), N0.455-480.

7. FREPD (2015): The Foundation for Research on Educational Planning and Development (FREPD), Dhaka, Bangladesh.

8. Hekela, L.P. (2014): Exploring Factors Contributing to Female Students Dropout Rates in Community Secondary Schools in Tanzania: A Case of Mbinga District, Unpublished Master Dissertation, Administration Planning and Policy Studies, Open University of Tanzania.

9. Hussain, D.A., Salfi, N.A. and Khan, D.T.A. (2011): Causes of Students' Dropout at Primary Level in Pakistan: An Empirical Study, International Journal of Humanities and Social Science, 1(12).

10. ILO (2004): Child Labour and Responses: Overview Note-Bangladesh. Dhaka.

11. Islam, M.N. and Pavel, T. (2011): Factors Contributing Towards Dropout at Undergraduate Level: An Analysis, $5(1)$.

12. Juneja, N. (2001): Primary Education for All in the City of Mumbai, India: The Challenge Set by Local Actors. School Mapping and Local-Level Planning.Paris: UNESCO.

13. Latif, A.H. (2005): Need Assessment of Early Childhood Care and Education in Bangladesh, Bangladesh Education Journal, 4 (2). 
14. Majumdar, M. (2001): Child Labour as a Human Security Problem: Evidence from India, Oxford Development Studies, 29(3), pp. 279-304.

15. Mujeri, M.K. (2010): The Right Based Approach to Education in Bangladesh, Bangladesh Development Studies, XXXIII (1\&2).

16. Shadreck, M. (2013): School Based Factors and Dropout Phenomena: a Study of Zhomba Cluster Secondary Schools in Gokwe District of Zimbabwe, Journal of Educational and Social Research, 3 (1).

17. Shahidul, S.M. and Karim, A.H.M.Z. (2015): Factors Contributing to School Dropout among the Girls: A Review of Literature, European Journal of Research and Reflection in Educational Sciences, 3(2).

18. UNICEF (2008): Child Labor and School Attendance: Evidence from MICS to DHS Surve, New York, USA: UNICEF.

19. Zaman, M. M. (2014): Dropout at Primary and Secondary Level A Challenge to Ensure Rights to Education for the Government of Bangladesh, Unpublished Dissertation, Institute of Government Studies (IGS), BRAC University, Dhaka, Bangladesh. 